\title{
Long term breast cancer screening in Nijmegen, The Netherlands: the nine rounds from 1975-92
}

Johannes D M Otten, Jos A A M van Dijck, Petronella G M Peer, Huub Straatman, André L M Verbeek, Marcel Mravunac, Jan H C L Hendriks, Roland Holland

\begin{abstract}
Study objective - To assess the performance of breast cancer screening in different age categories over two decades. Design - Important determinants of reduced breast cancer mortality such as attendance, mammography performance, cancer detection, and disease stage were recorded.
\end{abstract}

Setting - Nijmegen, The Netherlands, 1975-92.

Subjects - Since 1975 more than 40000 women aged 35 years and older have been invited biennially for breast screening in a population based project in Nijmegen.

Main results - Rates of attendance, referral, detection, and disease stage were calculated, as well as the specificity of screening mammography and the predictive value of referral and biopsy. From round 3 onwards, the attendance rate of women younger than 50 years stabilised at $70 \%$, in women of $50-69$ years it was $62 \%$, and in women aged 70 and over it was $22 \%$. In these three age categories, the referral rates of a positive screening mammography per 1000 screened women were $4 \cdot 9,6 \cdot 2$, and $11 \cdot 8$, respectively. Specificity rates were between $99 \%$ and $100 \%$. Current predictive values of referral were high: in the specific age categories $39 \%, 59 \%$, and $68 \%$ of the referred women had cancer. Detection rates remained fairly stable over the rounds $4-9$, at $1.9,3.6$, and 8.0 cancers per 1000 screened women. In the two year period between screening the numbers of interval cancers per 1000 screened women were $2 \cdot 2,2 \cdot 2$, and $2 \cdot 9$, for the three age categories respectively. With regard to invasive cancers detected during screening, the percentage of small tumours ( $\leq 20 \mathrm{~mm}$ on the mammogram) was $84 \%$ in each age category. For women younger than $\mathbf{5 0}$ years, the proportion of intraductal carcinoma in all the cancers detected at screening was $40 \%$, while it was $15 \%$ in the other age categories.

Conclusion - Throughout the nine rounds, the screening outcomes were found to be adequate, particularly considering the high specificity rate and the predictive value of referral without the interference of a low detection rate. Although the occurrence of interval cancers seemed high, it was similar to other screening programmes. Despite a relatively low referral rate, the ratios of screen detected versus interval cancer cases were favourable. Well organised screening programmes can achieve good mammography results without too many false positives. It is important that women continue to participate in a screening programme because cancer can still be detected even after several successive negative screening examinations.

\section{(f Epidemiol Community Health 1996;50:353-358)}

The generally accepted conclusion from randomised trials is that regular mammographical screening results in a $20-40 \%$ reduction in breast cancer mortality. ${ }^{1-6}$ For current and newly started programmes, it is important to have some idea of the screening outcomes that may be expected. As determinants for expected reductions in breast cancer mortality in the population, rates of attendance and detection as well as disease stage need to be assessed. Measures such as positive predictive value in the case of referral for further diagnostic evaluation, specificity rate, and predictive value of biopsy, play important roles in community health care and economics.

The breast cancer screening programme in Nijmegen started in 1975. Women are sent an invitation for a screening mammography once every two years. Up to the ninth round, more than 40000 women had been invited. The findings of these nine screening rounds are presented, stratified into the age categories $<50,50-69$, and $\geq 70$ years at each invitation, which also enabled us to study age specific trends in screening mammography performance.

\section{Methods}

THE SCREENING PROGRAMME

The population based programme in the city of Nijmegen (145000 inhabitants) offered nine rounds of screening with an interval of two years. In the first screening round, conducted in 1975-76, all the women born between 1910 and 1939 were sent a personal letter inviting them to participate. In the subsequent screening rounds, women born before 1910 were also invited. After the fourth round, women born between 1940 and 1944 also received an invitation and after the fifth round those born in 1945 were invited. From round 6 onwards, all the women born before 1947 were invited. In the ninth round, women aged 70 years and older were offered the opportunity to undergo 
Table 1 Number of invited, screened, referred and biopsied women and number of cancers at screening rounds, biopsy, and in the interscreening period of two years

\begin{tabular}{|c|c|c|c|c|c|c|c|c|c|}
\hline & 1st round & 2nd round & 3rd round & 4th round & Sth round & 6th round & 7 th round & 8th round & 9th round \\
\hline \multicolumn{10}{|l|}{ All ages } \\
\hline Invited & 23210 & 30553 & 29004 & 28033 & 29978 & 30596 & 30200 & 28960 & 26435 \\
\hline Screened & 19702 & 19787 & 16632 & 15111 & 16170 & 16482 & 16480 & 15219 & 13201 \\
\hline First screening* & 19702 & 4056 & 621 & 387 & 3054 & 1477 & 1380 & 498 & 100 \\
\hline Referred & 254 & 203 & 127 & 128 & 110 & 85 & 98 & 85 & 90 \\
\hline Cancer at screening† & $75(9)$ & $79(8)$ & $53(9)$ & $47(8)$ & $57(11)$ & $60(17)$ & $57(9)$ & $53(8)$ & $60(10)$ \\
\hline Biopsy & 182 & 142 & 98 & 88 & 79 & 69 & 77 & 61 & 65 \\
\hline Cancer at biopsy & 72 & 74 & 50 & 40 & 54 & 56 & 52 & 40 & 47 \\
\hline Interval cancert & $32(3)$ & 37 (3) & $30(0)$ & $35(4)$ & $26(0)$ & $34(3)$ & $43(1)$ & $42(1)$ & $28(2)$ \\
\hline \multicolumn{10}{|c|}{ Women under 50 y at screening } \\
\hline Invited & 11102 & 9238 & 7544 & 6058 & 8294 & 7960 & 7636 & 5663 & 3841 \\
\hline Screened & 9681 & 7165 & 5509 & 4281 & 5910 & 5642 & 5356 & 3931 & 2621 \\
\hline First screening* & 9681 & 466 & 145 & 113 & 2854 & 1142 & 1124 & 234 & 44 \\
\hline Referred & 108 & 63 & 34 & 33 & 30 & 19 & 20 & 20 & 13 \\
\hline Cancer at screening $f$ & $21(5)$ & $12(1)$ & $8(2)$ & $7(4)$ & $8(3)$ & $10(5)$ & $8(4)$ & $11(3)$ & $8(2)$ \\
\hline Biopsy & 71 & 42 & 26 & 26 & 21 & 15 & 17 & 16 & 12 \\
\hline Cancer at biopsy & 20 & 12 & 7 & 6 & 8 & 9 & 8 & 10 & 8 \\
\hline Interval cancerf & $15(1)$ & $9(2)$ & $10(0)$ & $12(1)$ & $5(0)$ & $17(2)$ & $8(0)$ & $12(0)$ & $6(0)$ \\
\hline \multicolumn{10}{|c|}{ Women aged 50-69 y at screening $\ddagger$} \\
\hline Invited & 12108 & 14849 & 14752 & 14808 & 14299 & 14566 & 14319 & 14801 & 14306 \\
\hline Screened & 10021 & 10334 & 9340 & 9119 & 8588 & 8942 & 9055 & 9352 & 9306 \\
\hline First screening* & 10021 & 1302 & 215 & 195 & 145 & 268 & 202 & 223 & 53 \\
\hline Referred & 146 & 100 & 70 & 65 & 62 & 48 & 54 & 45 & 62 \\
\hline Cancer at screening $\dagger$ & $54(4)$ & $44(6)$ & $33(5)$ & $25(4)$ & $38(6)$ & $34(8)$ & $32(2)$ & $28(4)$ & $40(7)$ \\
\hline Biopsy & 111 & 71 & 55 & 44 & 46 & 40 & 41 & 31 & 42 \\
\hline Cancer at biopsy & 52 & 41 & 32 & 21 & 36 & 33 & 29 & 20 & 31 \\
\hline Interval cancert & $17(2)$ & $23(1)$ & $18(0)$ & $19(3)$ & $14(0)$ & $11(0)$ & $30(1)$ & $22(1)$ & $21(2)$ \\
\hline \multicolumn{10}{|c|}{ Women aged $70 y$ or older at screening } \\
\hline Invited & - & 6466 & 6708 & 7167 & 7385 & 8070 & 8245 & 8496 & 8288 \\
\hline Screened & - & 2288 & 1783 & 1711 & 1672 & 1898 & 2069 & 1936 & 1274 \\
\hline First screening* & - & 2288 & 261 & 79 & 55 & 67 & 54 & 41 & 3 \\
\hline Referred & - & 40 & 23 & 30 & 18 & 18 & 24 & 20 & 15 \\
\hline Cancer at screeningt & - & $23(1)$ & $12(2)$ & $15(0)$ & $11(2)$ & $16(4)$ & $17(3)$ & $14(1)$ & $12(1)$ \\
\hline Biopsy & - & 29 & 17 & 18 & 12 & 14 & 19 & 14 & 11 \\
\hline Cancer at biopsy & - & 21 & 11 & 13 & 10 & 14 & 15 & 10 & 8 \\
\hline Interval cancert & - & $5(0)$ & $2(0)$ & $4(0)$ & $7(0)$ & $6(1)$ & $5(0)$ & $8(0)$ & $1(0)$ \\
\hline
\end{tabular}

*Number of women screened for the first time out of the total number of screened women.

In parentheses, the number of ductal carcinoma in situ out of the total number of cancers

$\ddagger$ In the first screening round only women aged 50-65 y.

screening, but had to make an appointment for a screening examination themselves.

At the screening centre, single view mammography was carried out in subsequent screening rounds. Initially a lateral view and from the fourth round onwards a mediolateraloblique view was taken, using a General Electric (CGR) $600 \mathrm{~T}$. The films were processed and first studied by the radiographer. A second view was taken in the craniocaudal direction of one breast if the quality was not good enough for evaluation (for example, because of overprojection), or of both breasts if a lesion was suspected. All the films were read by at least one and mostly two radiologists, who decided whether referral was necessary. Referral was based on characteristics such as density and specific microcalcifications or indirect signs such as asymmetry of the breast tissue or nipple retraction.

The general practitioners of women whose mammograms suggested possible malignancy were informed of this and advised to refer these women to one of the two hospitals in Nijmegen, where complete mammography and physical examination were conducted. The so called "diagnostic mamma-team", comprising radiologists, surgeons, and pathologists, decided whether any further diagnostic tests were needed.

The screening outcomes over the first six screening rounds (1975-86) presented by birth cohort have been published before. ${ }^{7}$ Data from the subsequent three screening rounds (198792) are now available and add substantially to the earlier results.
STATISTICAL METHODS

For each round, all the numbers and rates were calculated according to age at the specific screening invitation. Specificity denotes the number of true negative screening results in relation to the total number of "non-cancer" women. This was calculated as the number of negative screening results divided by the total number of screened women minus the number of patients detected by screening. ${ }^{8}$

\section{Results}

The outcomes of all nine rounds of the screening programme are presented in table 1 . Table 2 presents the effect measures calculated from these outcomes.

\section{ATTENDANCE}

In the period 1975-92, a total of 41087 women were screened with 148699 mammograms. For women younger than 50 years the attendance (fig 1) remained fairly stable, at about $70 \%$, between 1981 and 1992 (rounds 4-9). The attendance rate for women aged 50-69 years stabilised at slightly more than $60 \%$. For women aged 70 and older, the attendance rate had declined to below $20 \%$ by the ninth round. In the ninth round approximately $35 \%$ of all the women who had been invited at least eight times had been screened 8 times (always); $20 \%$ had been screened 6-7 times, 20\% 4-5 times and $25 \%$ less than 3 times. Approximately $10 \%$ of the women who were invited to the ninth round had never been screened. 
Table 2 Statistical screening outcomes in three age groups over the nine screening rounds

\begin{tabular}{|c|c|c|c|c|c|c|c|c|c|}
\hline & 1st round & 2nd round & 3rd round & 4th round & 5th round & 6th round & 7 th round & 8th round & 9 th round \\
\hline \multicolumn{10}{|l|}{ All ages } \\
\hline Attendance (\%) & $84 \cdot 9$ & $64 \cdot 8$ & $57 \cdot 3$ & 53.9 & 53.9 & 53.9 & $54 \cdot 6$ & $52 \cdot 6$ & $49 \cdot 9$ \\
\hline Referral $(\%)$ & $12 \cdot 9$ & $10 \cdot 3$ & $7 \cdot 6$ & $8 \cdot 5$ & $6 \cdot 8$ & $5 \cdot 2$ & $5 \cdot 9$ & $5 \cdot 6$ & $6 \cdot 8$ \\
\hline Detection Screening (\%) & $3 \cdot 8$ & $4 \cdot 0$ & $3 \cdot 2$ & $3 \cdot 1$ & $3 \cdot 5$ & $3 \cdot 6$ & $3 \cdot 5$ & $3 \cdot 5$ & $4 \cdot 5$ \\
\hline $\mathrm{PV}+$ referral $(\%)$ & $29 \cdot 5$ & $38 \cdot 9$ & $41 \cdot \overline{7}$ & $36 \cdot 7$ & $51 \cdot 8$ & $70 \cdot 6$ & $58 \cdot 2$ & $62 \cdot 4$ & $66 \cdot 7$ \\
\hline PV + biopsy (\%) & $39 \cdot 6$ & $52 \cdot 1$ & $51 \cdot 0$ & $45 \cdot 5$ & $68 \cdot 4$ & $81 \cdot 2$ & $67 \cdot 5$ & $65 \cdot 6$ & $72 \cdot 3$ \\
\hline Specificity (\%) & $99 \cdot 1$ & $99 \cdot 4$ & $99 \cdot 6$ & $99 \cdot 5$ & $99 \cdot 7$ & $99 \cdot 8$ & $99 \cdot 8$ & $99 \cdot 8$ & $99 \cdot 8$ \\
\hline Diagnosis Interval (\%) & $1 \cdot 6$ & 1.9 & $1 \cdot 8$ & $2 \cdot 3$ & $1 \cdot 6$ & $2 \cdot 1$ & $2 \cdot 6$ & $2 \cdot 8$ & $2 \cdot 1$ \\
\hline Screen $/(\text { Screen }+ \text { Inter })^{*}(\%)$ & $70 \cdot 1$ & $68 \cdot 1$ & 63.9 & $57 \cdot 3$ & $68 \cdot 7$ & $63 \cdot 8$ & $57 \cdot 0$ & $55 \cdot 8$ & $68 \cdot 2$ \\
\hline \multicolumn{10}{|l|}{ Women under 50 y at screening } \\
\hline Attendance (\%) & $87 \cdot 2$ & $77 \cdot 6$ & $73 \cdot 0$ & $70 \cdot 7$ & $71 \cdot 3$ & $70 \cdot 9$ & $70 \cdot 1$ & $69 \cdot 4$ & $68 \cdot 2$ \\
\hline Referral $(\%)$ & $11 \cdot 2$ & $8 \cdot 8$ & $6 \cdot 2$ & $7 \cdot 7$ & $5 \cdot 1$ & $3 \cdot 4$ & $3 \cdot 7$ & $5 \cdot 1$ & $5 \cdot 0$ \\
\hline Detection Screening (\%) & $2 \cdot 2$ & $1 \cdot 7$ & $1 \cdot 5$ & $1 \cdot 6$ & $1 \cdot 4$ & $1 \cdot 8$ & 1.5 & $2 \cdot 8$ & $3 \cdot 1$ \\
\hline$P V+$ referral $(\%)$ & $19 \cdot 4$ & $19 \cdot 0$ & $23 \cdot 5$ & $21 \cdot 2$ & $26 \cdot 7$ & $52 \cdot 6$ & $40 \cdot 0$ & $55 \cdot 0$ & 61.5 \\
\hline PV + biopsy (\%) & $28 \cdot 2$ & $28 \cdot 6$ & $26 \cdot 9$ & $23 \cdot 1$ & $38 \cdot 1$ & $60 \cdot 0$ & $47 \cdot 1$ & $62 \cdot 5$ & $66 \cdot 7$ \\
\hline Specificity (\%) & $99 \cdot 1$ & $99 \cdot 3$ & $99 \cdot 5$ & $99 \cdot 4$ & $99 \cdot 6$ & $99 \cdot 8$ & $99 \cdot 8$ & $99 \cdot 8$ & $99 \cdot 8$ \\
\hline Diagnosis Interval (\%) & 1.5 & $1 \cdot 3$ & $1 \cdot 8$ & $2 \cdot 8$ & $0 \cdot 8$ & $3 \cdot 0$ & 1.5 & $3 \cdot 1$ & $2 \cdot 3$ \\
\hline Screen/(Screen + Inter $)^{*}(\%)$ & $58 \cdot 3$ & $57 \cdot 1$ & $44 \cdot 4$ & $36 \cdot 8$ & $61 \cdot 5$ & $37 \cdot 0$ & $50 \cdot 0$ & $47 \cdot 8$ & $57 \cdot 1$ \\
\hline \multicolumn{10}{|l|}{ Women aged 50-69 y at screening } \\
\hline Attendance $(\%)$ & $82 \cdot 8$ & $69 \cdot 6$ & $63 \cdot 3$ & $61 \cdot 6$ & $60 \cdot 1$ & $61 \cdot 4$ & $63 \cdot 2$ & $63 \cdot 2$ & $65 \cdot 0$ \\
\hline Referral (\%) & $14 \cdot 6$ & $9 \cdot 7$ & $7 \cdot 5$ & $7 \cdot 1$ & $7 \cdot 2$ & $5 \cdot 4$ & $6 \cdot 0$ & $4 \cdot \overline{8}$ & $6 \cdot 7$ \\
\hline Detection Screening (\%) & $5 \cdot 4$ & $4 \cdot 3$ & $3 \cdot 5$ & $2 \cdot 7$ & $4 \cdot 4$ & $3 \cdot 8$ & $3 \cdot 5$ & $3 \cdot 0$ & $4 \cdot 3$ \\
\hline $\mathrm{PV}+$ referral $(\%)$ & $37 \cdot 0$ & $44 \cdot 0$ & $47 \cdot 1$ & $38 \cdot 5$ & $61 \cdot 3$ & $70 \cdot 8$ & $59 \cdot 3$ & $62 \cdot 2$ & $64 \cdot 5$ \\
\hline PV + biopsy (\%) & $46 \cdot 8$ & $57 \cdot 7$ & $58 \cdot 2$ & $47 \cdot 7$ & $78 \cdot 3$ & $82 \cdot 5$ & $70 \cdot 7$ & $64 \cdot 5$ & $73 \cdot 8$ \\
\hline Specificity (\%) & $99 \cdot 1$ & $99 \cdot 5$ & $99 \cdot 6$ & $99 \cdot 6$ & $99 \cdot 7$ & $99 \cdot 8$ & $99 \cdot 8$ & $99 \cdot 8$ & $99 \cdot 8$ \\
\hline Diagnosis Interval (\%) & 1.7 & $2 \cdot 2$ & 1.9 & $2 \cdot 1$ & $1 \cdot 6$ & $1 \cdot 2$ & $3 \cdot 3$ & $2 \cdot 4$ & $2 \cdot 3$ \\
\hline Screen/(Screen + Inter $)^{*}(\%)$ & $76 \cdot 1$ & $6 \overline{5} \cdot \overline{7}$ & $64 \cdot 7$ & $56 \cdot 8$ & $73 \cdot 1$ & $75 \cdot 6$ & $51 \cdot 6$ & $56 \cdot 0$ & $65 \cdot 6$ \\
\hline \multicolumn{10}{|c|}{ Women aged $70 y$ or older at screening } \\
\hline Attendance $(\%)$ & - & $35 \cdot 4$ & $26 \cdot 6$ & $23 \cdot 9$ & $22 \cdot 6$ & $23 \cdot 5$ & $25 \cdot 1$ & $22 \cdot 8$ & $15 \cdot 4$ \\
\hline Referral (\%) & - & $17 \cdot 5$ & $12 \cdot 9$ & $17 \cdot 5$ & $10 \cdot 8$ & $9 \cdot 5$ & $11 \cdot 6$ & $10 \cdot 3$ & $11 \cdot 8$ \\
\hline Detection Screening (\%) & - & $10 \cdot 1$ & $6 \cdot 7$ & $8 \cdot 8$ & $6 \cdot 6$ & $8 \cdot 4$ & $8 \cdot 2$ & $7 \cdot 2$ & $9 \cdot 4$ \\
\hline PV + Referral (\%) & - & $57 \cdot 5$ & $52 \cdot 2$ & $50 \cdot 0$ & $61 \cdot 1$ & 88.9 & $70 \cdot 8$ & $70 \cdot 0$ & $80 \cdot 0$ \\
\hline PV + Biopsy (\%) & - & $72 \cdot 4$ & $64 \cdot 7$ & $72 \cdot 2$ & $83 \cdot 3$ & $100 \cdot 0$ & $78 \cdot 9$ & $71 \cdot 4$ & $72 \cdot 7$ \\
\hline Specificity (\%) & - & $99 \cdot 2$ & $99 \cdot 4$ & $99 \cdot 1$ & $99 \cdot 6$ & $99 \cdot 8$ & $99 \cdot 7$ & $99 \cdot 7$ & $99 \cdot 8$ \\
\hline Diagnosis Interval (\%) & - & $2 \cdot 2$ & $1 \cdot 1$ & $2 \cdot 3$ & $4 \cdot 2$ & $3 \cdot 2$ & $2 \cdot 4$ & $4 \cdot 1$ & $0 \cdot 8$ \\
\hline Screen/(Screen + Inter $)^{*}(\%)$ & - & $82 \cdot 1$ & $85 \cdot 7$ & $78 \cdot 9$ & $61 \cdot 1$ & $72 \cdot 7$ & $77 \cdot 3$ & $63 \cdot 6$ & $92 \cdot 3$ \\
\hline
\end{tabular}

* Ratio of the number of screen detected $v$ summation of the number of screen detected and interval cancers.

+ In the first screening round only women aged 50-65 y.

+ In the first screening round only
$P V+=$ predictive value positive.

REFERRAL

For all the age categories, the referral rates for further evaluation were highest in the first screening round (see table 2). At that initial screening the age specific referral rates per 1000 screened women were $11 \cdot 2,14 \cdot 6$, and $17 \cdot 5$ for the three groups respectively. During the course of the programme, these figures declined to an

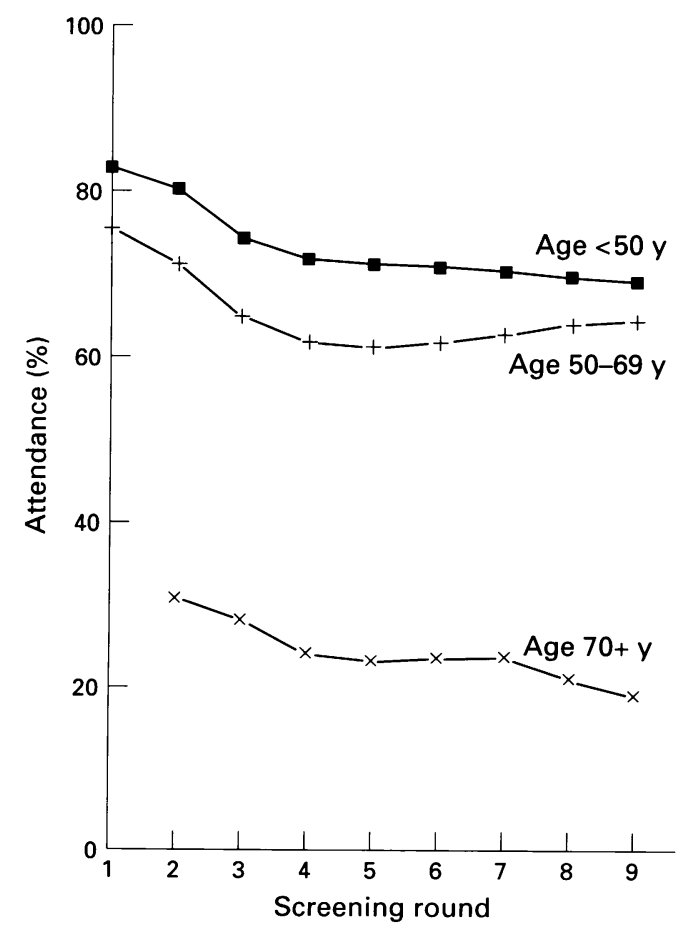

Figure 1 Attendance per 100 women invited (three rounds moving average). average value (rounds 4-9) of 4.9 for women younger than 50 years and $6 \cdot 2$ for those aged 50-69. For the older women, the referral rate stabilised at 11.8 per 1000 screened women.

SPECIFICITY AND PREDICTIVE VALUE

In the first round the overall specificity was $99 \cdot 1 \%$, which increased to $99 \cdot 8 \%$ by the sixth round and remained stable thereafter.

The positive predictive values $(\mathrm{PV}+\mathrm{ve})$ of referral (fig 2), that is, the number of cancers detected among 100 positive screening tests (referred women), showed a sharp increase after the fourth round. For the women younger than 50 years, the PV+ve increased from $20 \%$ to $62 \%$ in the ninth round. For the women aged 50-69 years and the women aged 70 years and older, the PV + ve increased from about $37 \%$ and $58 \%$, to $65 \%$ and $80 \%$, respectively.

About $70 \%$ of all the referred women underwent a biopsy. The positive predictive value of biopsy designates the number of cancers among the women who had a biopsy. This PV + ve of biopsy converged from $40 \%$ to $72 \%$ in round 9.

\section{BREAST CANCER}

After the third round, detection rates of breast cancer (lobular carcinoma in situ excluded) remained stable over the rounds for all three age groups - at approximately $1.9,3.6$, and $8 \cdot 0$ cancers per 1000 women screened (fig 3 ).

From round 4 onwards, and considering all cancers, women younger than 50 years had a higher proportion of in situ carcinomas $(40 \%$ 


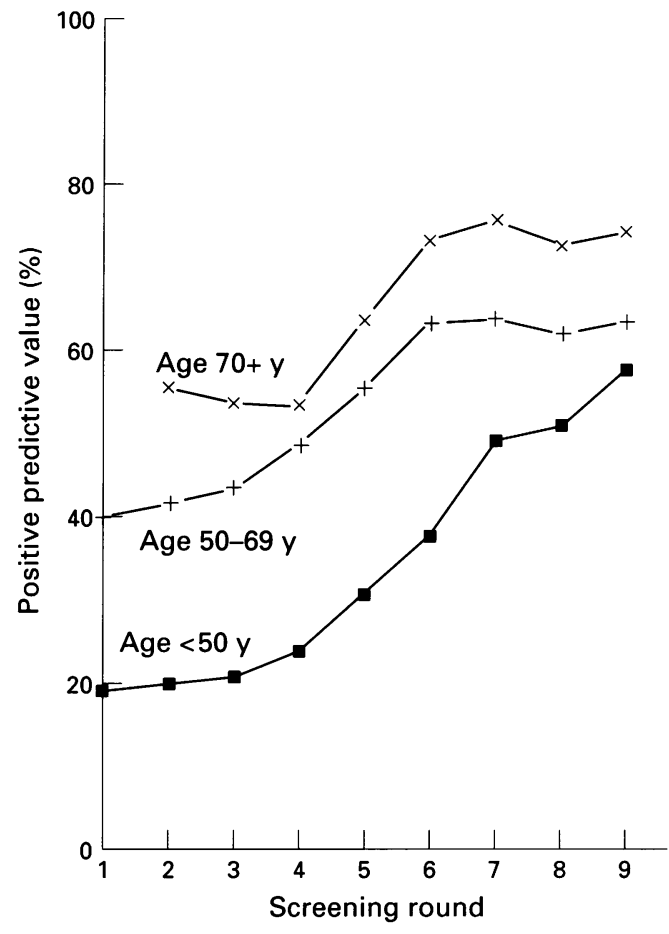

Figure 2 Positive predictive value of referral (three rounds moving average).

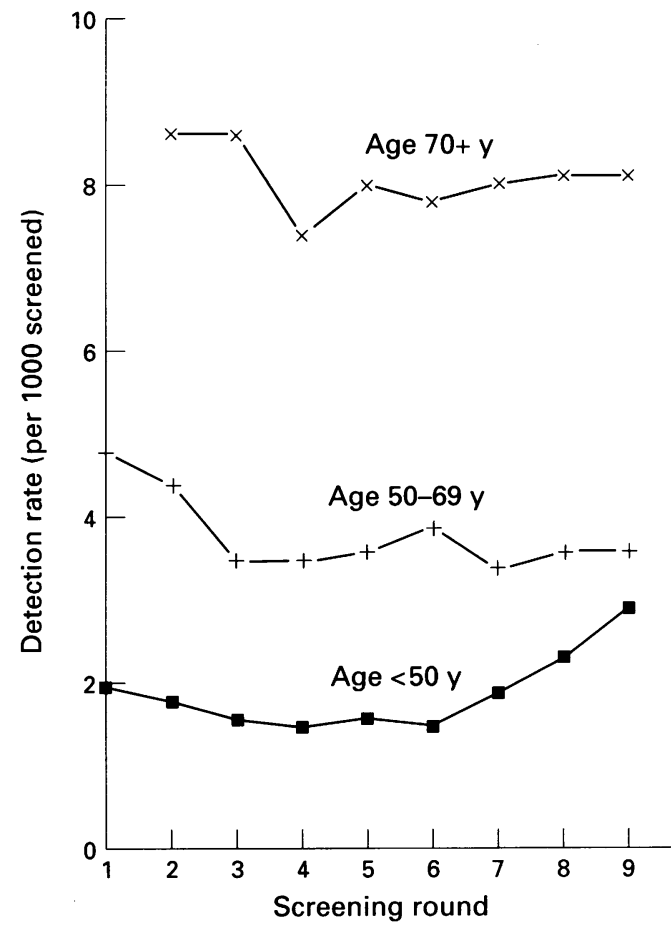

Figure 3 Breast cancer detection per 1000 women screened (three rounds moving average).

$(21 / 52))$, than the women in the age groups $50-69$ years and 70 years and older $(16 \%$ (31) $196)$ and $13 \%(11 / 84)$ respectively).

The percentages of small $(\leq 20 \mathrm{~mm})$ tumours in invasive cancers detected by screening were $83.9 \%(26 / 31)$ for the age group younger than 50 years, $84 \cdot 2 \%(139 / 165)$ for the middle age group, and $83.8 \%(62 / 74)$ for the patients of 70 years and older.

The interval cancer rates in the two year period between screening (fig 4) were fairly stable over rounds 4-9 for the age categories younger than 50 and 50-69 years; there were $2 \cdot 2$ interval cancers per 1000 women screened. For women aged 70 years and older, the figures increased from 1.7 (rounds 2-3) to 2.9 per 1000 screened women in rounds 4-9. The interval cancer rates in the first year of the two year interscreening period were $0.83,0.52$, and 0.66 respectively per 1000 screened women for the three age categories. The ratios of the number of cancers detected by screening versus the summation of the number of screen detected and interval cancers remained fairly stable at $46 \%, 63 \%$, and $73 \%$ (rounds $4-9$ ), respectively.

\section{Discussion}

Attendance is an important determinant of future breast cancer mortality reduction in the total community who are offered a screening programme. Almost all trials have presented their attendance rates according to age at the initial invitation. Mostly, the target populations comprised a very large age span. As many of the participants will reach the oldest age category during the course of the screening programme, it is not surprising that clear reductions in attendance are observed when data are presented according to age at entry.

Most of the newly started programmes go beyond the trial sphere and have a target population in the age category $50-70$ years. Compliance at the initial screening examination in Nijmegen was inversely related to age. It was high (83\%) in the $50-70$ year age category. A decline in attendance was observed in all age groups at the second screening examination. Thereafter, the attendance rate stabilised at between 60 and $70 \%$ for the age categories under 50 and $50-69$ years. This level of attendance is considered acceptable. ${ }^{9}$ No special effort was undertaken in Nijmegen to maintain this attendance rate other than sending a personal letter of invitation, including one reminder if necessary, every two years. For the age category 70 years and older, comorbidity, impaired functional status, and reduced social support influenced attendance. Although the low attendance in this oldest age category will affect the effectiveness of the screening programme at the population level, the group of older women who participate can still benefit from screening. ${ }^{10}$

Of particular interest were the women aged $50-51$ years in 1975 at the start of the programme. These women had 10 scheduled screening sessions ahead of them up to the age of 70 years. At the first invitation, compliance was $85 \%$, at the second it was $77 \%$ with a stable rate of $68 \%$ thereafter up to and including the ninth round.

Another measure that evaluates the efficacy of screening is the breast cancer detection rate. In the first screening round, a worthwhile detection rate in the screened women needed to be a multiple of the expected annual incidence rate. ${ }^{9}$ This expected annual incidence rate was not recorded directly but it could be derived from the expected rate in the total population 


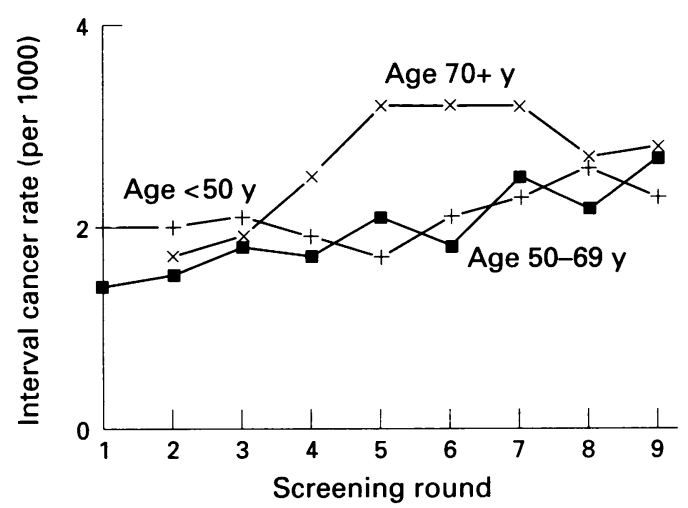

Figure 4 Two year interval cancer rates per 1000 women screened (three rounds moving average).

and the rate in the group who did not attend. To calculate the expected incidence, figures from the city of Arnhem (a neighbouring city without a screening programme) were used. ${ }^{11}$ The detection rate at the first screening round was almost three times the expected annual incidence rate. This ratio expressed a favourable outcome for the lead time distribution, which in turn gave an indication of the average length of time that the diagnosis was advanced by screening. The ratio between the first detection rate and the expected incidence rate in Nijmegen was similar to the ratio reported in the results of the Swedish trials. $^{12}$

It was remarkable that there was no reduction in the detection rates across the nine screening rounds. In all the age categories, the breast cancer detection rate remained fairly stable and only showed an initial decline after the first screening round. Obviously, breast cancer keeps on developing in women of all ages. No reasonable biological explanation can be given for the increase in detection in the youngest group from round 8 onwards. No new younger birth cohorts were invited for screening in Nijmegen after the seventh round, and the absolute numbers of breast cancer cases were fairly small, approximately 10 at each round which may be responsible for the increase in the detection rate. It is also possible that the mammography technique has improved during the same period and yielded more mammographically detectable preclinical cancers, including intraductal carcinomas. This proposition is refuted, however, by the observation of high incidence rates of interval cancers. Even after the fourth screening round, for each two screen detected cancers, one interval cancer

Table 3 Detection rate and interval cancer rate for the breast cancer demonstration project (BCDP), Sweden, and Nijmegen

\begin{tabular}{|c|c|c|c|c|}
\hline & $\begin{array}{l}\text { 1st round } \\
\text { detection } \\
\text { rate }(\%)\end{array}$ & $\begin{array}{l}\text { Subsequent } \\
\text { rounds detection } \\
\text { rate (\%) }\end{array}$ & $\begin{array}{l}\text { 1st round, } 1 \text { st } \\
\text { year interval } \\
\text { cancer rate (\%) }\end{array}$ & $\begin{array}{l}\text { Subsequent } 1 \text { st } \\
\text { year interval } \\
\text { cancer rate (\%) }\end{array}$ \\
\hline \multicolumn{5}{|c|}{ Women aged 35-49 y at entry } \\
\hline BCDP & $3 \cdot 0$ & 1.9 & $0 \cdot 6$ & $0 \cdot 8$ \\
\hline Nijmegen & $2 \cdot 2$ & $1 \cdot 7$ & $0 \cdot 4$ & 0.8 \\
\hline Sweden & - & - & - & - \\
\hline \multicolumn{5}{|c|}{ Women aged 50-69 y at entry } \\
\hline BCDP & $7 \cdot 9$ & $3 \cdot 3$ & $1 \cdot 0$ & 0.9 \\
\hline Nijmegen & $5 \cdot 6$ & $4 \cdot 1$ & 0.6 & 0.6 \\
\hline Sweden & $6 \cdot 8$ & $4 \cdot 3$ & $0 \cdot 3$ & 0.4 \\
\hline
\end{tabular}

was diagnosed in the interscreening period of two years; in the women younger than 50 years the ratio was even one to one.

The unaggressive attitude to mammographic screening in The Netherlands compared with the USA has been criticised. ${ }^{13-15}$ The Nijmegen radiologists showed far less inclination to refer women with non-specific mammographical signs for further diagnostic tests. This policy is recognisable in the Nijmegen project through the low referral rates, though low referral was not achieved at the cost of the detection rate, which was similar to other screening programmes. $^{416}$

Assessment of this issue through reviewing published reports (meta-analysis) is handicapped by the fact that very few data are available from screening projects with long term, well documented sets of mammograms and clinical follow up in the USA. Only the breast cancer demonstration project ${ }^{17}$ mentions screen detected and interval cancers. The detection rate during the first year was very high (table $3^{17}$ ) but declined towards the level seen in Nijmegen in the consecutive years. In addition, the interval cancer rates were fully comparable with the Nijmegen rates in the first year of the two years' interscreening period. Comparison of interval cancers as a proportion of underlying incidence (incidence in the adjacent population of Arnhem) were similar to other studies. ${ }^{1819}$

A prerequisite for an effective programme is a favourable tumour size at presentation. The proportion of small tumours in patients in the age category 50-69 years was similar to that in other studies. ${ }^{42021}$ The issue of the ductal carcinoma in situ (DCIS) must also be raised, as this lesion is diagnosed relatively frequently in breast cancer screening projects. DCIS constitute about $10-20 \%$ of all breast cancers detected in the screened population, ${ }^{22}$ whereas the detection rate is only $3-5 \%$ in clinical practice. In our series, the relative frequency of ductal carcinoma in situ (DCIS) among all cancers from the fourth round onwards, was approximately $40 \%$ in the age category $<50$ years, $16 \%$ in the $50-69$ year old category, and $13 \%$ in the elderly. The absolute detection rates of DCIS in the specific age groups in Nijmegen during round 7 up to and including 9 , the current steady state, were $0 \cdot 75 / 10^{3} \quad(=9 /$ 11939), $0.50 / 10^{3}(=14 / 27651)$ and $0.95 / 10^{3}$ (=5/5258), respectively. This forms a " $\mathrm{J}$ " shape with the elderly at the top, the 50-69 year olds at the bottom, and the younger group somewhere in between.

The extent to which the "J" shaped detection rate of DCIS across the age groups is (partly) caused by clinically non-relevant DCIS in the group of women younger than 50 years who never develop an invasive tumour is open to speculation. Comedo and non-comedo (poorly and well differentiated) histopathological typing is currently performed on all DCISs to provide insight into the pathogenesis of DCIS and suitable methods of treatment. ${ }^{2324}$ Even after the latest treatment results published in $1993,{ }^{25}$ it has still not been indisputably resolved whether the treatment of choice for DCIS or its subtype diagnosed on the basis of 
mammography and histology (whether or not displaying multicentricity), should be mastectomy, lumpectomy plus radiotherapy, or lumpectomy alone (that is, wait and see). The subject becomes even more urgent in countries with recently launched screening programmes such as in Sweden, the UK, and The Netherlands, because it can be expected that they will have to deal with DCIS in increasing numbers of women. It has been estimated that screening will detect $250-300$ cases of DCIS each year in the Dutch national screening programme. $^{26}$

1 Shapiro S, Venet W, Strax P, Venet L. Current results of the breast cancer screening randomized trial: the Health Insurance Plan (HIP) of greater New York. In: Day NE Miller AB eds. Screening for breast cancer. Toronto: Hans Huber Publishers, 1988:3-15.

2 Rutqvist LE, Miller AB, Andersson I, et al. Reduced breastcancer mortality with mammography screening - an assessment of currently available data. Int $\mathcal{F}$ Cancer 1990;5 (suppl):76-84.

3 Wald N, Frost C, Cuckle H. Breast cancer screening: the current position. BMF 1991;302:845-6.

4 Tabàr L, Fagerberg G, Duffy SW, Day NE, Gad A, Gröntoft O. Update of the Swedish two-county program of mammographic screening for breast cancer. Radiol Clin North Am 1992;30:187-210.

5 Nyström L, Rutqvist LE, Wall S, et al. Breast cancer screening with mammography: overview of Swedish randomised trials. Lancet 1993;341:973-8.

6 Fletcher SW, Black W, Harris R, Rimer BK, Shapiro S. Report of the international workshop on screening fo breast cancer. F Natl Cancer Inst 1993;85:1644-56.

7 Peeters PHM, Verbeek ALM, Hendriks JHCL, Van Bon $\mathrm{MJH}$. Screening for breast cancer in Nijmegen. Report of 6 screening rounds, 1975-1986. Int $\mathcal{F}$ Cancer 1989;43: 226-30.

8 Brecht JG, Robra BP. A graphic method of estimating the specificity of screening programmes from incomplete follow-up data. Methods Inf Med 1987;26:53-8.

9 Day NE, Williams DRR, Khaw KT. Breast cancer screening programmes: the development of a monitoring and evaluation system. Br $\mathcal{f}$ Cancer 1989;59:954-8.

10 Van Dijck JAAM, Holland R, Verbeek ALM, Hendriks JHCL, Mravunac $M$. Efficacy of mammographic screening of the elderly: a case-referent study in the Nijmegen Program in The Netherlands. 7 Natl Cancer Inst 1994;86: Program
11 Verbeek ALM, Hendriks JHCL, Holland R, Mravunac M, Sturmans F, Day NE. Reduction of breast cancer mortality through mass screening with modern mammography. First results of the Nijmegen project, 1975-1981. Lancet 1984 i: $1222-4$.

12 Day NE, Walter SD, Tabár L, Fagerberg CJG, Collette HJA The sensitivity and lead time of breast cancer screening: a comparison of the results of different studies. In: Day NE Miller AB (eds.). Screening for breast cancer. Toronto: Hans Huber Publishers, 1988:105-9.

13 Kopans DB. Mammography screening for breast cancer. Cancer 1993;72:1809-12.

14 Moskowitz M. Breast cancer: age-specific growth rates and screening strategies. Radiology 1986;161:37-4

15 Van Dijck JAAM, Verbeek ALM, Hendriks JHCL, Holland $R$. The current detectability of breast cancer in a mammographic screening program. A review of the previous mammograms of interval and screen-detected cancers. Cancer 1993;72:1933-8.

16 Chamberlain J, Moss SM, Kirkpatrick AE, Michell M, Johns L. National Health Service breast screening programme results for 1991-2. BMF 1993;307:353-6.

17 American Cancer Society. The breast cancer detection demonstration project five year summary report. $\mathrm{Ca}$ Cancer monstration project five

18 Frisell J, Eklund G, Hellström L, Lidbrink E, Rutqvist LE Somell A. Randomized study of mammography screening - preliminary report on mortality in the Stockholm trial. Breast Cancer Res Treat 1991:18:49-56.

19 Woodman CBJ, Threlfall AG, Boggis CRM, Prior P. Is the three year breast screening interval too long? Occurrence of interval cancers in NHS breast screening programme's north western region. BMf 1995;310:224-6.

20 Anderson TJ, Lamb J, Donnan P, et al. Comparative pathology of breast cancer in a randomised trial of screening. $B r$ f Cancer 1991;64:108-13.

21 Paci E, Ciatto S, Buiatti E, Cecchini S, Palli D, Rossell Del Turco M. Early indicators of efficacy of breast cancer screening programmes. Results of the Florence district programme. Int $\mathcal{f}$ Cancer 1990;46:198-202.

22 Peeters PHM, Verbeek ALM, Zielhuis GA, Vooijs GP, Hendriks JHCL, Mravunac M. Breast cancer screening Hendriks JHCL, Mravunac M. Breast cancer screening in women over a

23 Holland R, Peterse JL, Millis RR, et al. Ductal carcinoma in situ: a proposal for a new classification. Semin Diagn Pathol 1994;11:167-80

24 Holland R, Conolly JL, Gelman R, et al. The presence of an extensive intraductal component following a limited excision correlates with prominent residual disease in the remainder of the breast. F Clin Oncol 1990;8:113-8.

25 Fisher B, Costantino J, Redmond C, et al. Lumpectomy compared with lumpectomy and radiation therapy for the treatment of intraductal breast cancer. N Engl f Med 1993; 328:1581-6.

26 De Koning HJ, Boer R, Van Ineveld BM, et al. Landelijke evaluatie van bevolkingsonderzoek naar borstkanker in Nedevaluatie van bevolkingsonderzoek naar borstkanker in NedGezondheidszorg, Erasmus Universiteit Rotterdam, 1993. 